\title{
Life history traits in Darwinula stevensoni (Crustacea: Ostracoda) from Southern European populations under controlled conditions and their relationship with genetic features
}

\author{
Andrea GANDOLFI*, Eletta B.A. TODESCHI, Valeria ROSSI and Paolo MENOZZI \\ Dipartimento di Scienze Ambientali, Università degli Studi di Parma, Parco Area delle Scienze, 43100 Parma, Italy \\ *e-mail corresponding author: andrea@dsa.unipr.it
}

\begin{abstract}
We describe life history traits of the ostracod Darwinula stevensoni through laboratory experiments. This small (about $0.7 \mathrm{~mm}$ ), ancient, obligate parthenogenetic species appeared to be particulary difficult to handle as its long life cycle (up to 3-4 years) has made lab experiments over several generations very difficult. D. stevensoni is an eurythermal and euryhaline species with low variability in size and shape (both of the carapace and the soft parts). Its genetic variability has also been found to be very low. Survival, clutch size, deposition timing and hatching were evaluated in acclimated and non-acclimated females from seven populations: six from Northern Italy and one from Spain. The samples were collected from three different habitats: four lakes, two streams and one spring. A genetic survey using starch gel electrophoresis had previously revealed that only Glucose phosphate isomerase (Gpi) locus was polymorphic. A clone, homozygous at Gpi locus, is the most common in lacustrine and spring habitats in the whole biogeographic range. Surprisingly, two heterozygous clones dominate in Northern Italian lotic environments. Enzymatic activity of heterozygous and homozygous genotypes at Gpi locus was assayed in order to evaluate the relationship between Gpi activity and fitness. Survival and developmental time were not affected by acclimation, while reproductive potential decreased in acclimated females. In females from running waters, reproduction started later and lasted for a shorter time, clutch size was smaller, and hatching percentage lower than females from lakes. These differences are not directly correlated with differences in enzymatic activities at Gpi locus. This does not rule out an overall genetic control of these characteristics since, in a parthenogenetic species, the whole genome is transmitted without recombination. We stress the intriguing case of $\mathrm{D}$. stevensoni in relation to the concept of the "general purpose genotype".
\end{abstract}

Key words: Darwinula stevensoni, habitats, populations, genotypes, enzyme activity

\section{INTRODUCTION}

In 1993, the paper by Butlin \& Griffiths (1993) on "ageing without sex" renewed scientific interest in the superfamily Darwinuloidea and, in particular, in the species Darwinula stevensoni Brady \& Robertson (1870). This species is assumed to reproduce by apomictic parthenogenesis like all unisexual non-marine ostracods (Butlin et al. 1998). No evidence of sexuality seems to have been found since the appearance of the species, $70 \mathrm{Ma}$, or the group, $250 \mathrm{Ma}$ (Chaplin et al. 1994; Judson \& Normark 1996; Schön et al. 1996; but see also Martens 1998). Male existence has not been satisfactorily recorded in any of the species of darwinulids, despite the long and rich fossil record (see Sohn 1987; Rossetti \& Martens 1996). Tetart (1978) described and illustrated 22 chromosomes in D. stevensoni: one pair was relatively longer while all the others were morphologically uniform. The finding of chromosomes impossible to sort in pairs supports the hypothesis of reproduction without meiosis for a long time (Birky 1996; Judson \& Normark 1996). According to Judson \& Normark (1996) this evidence qualifies the darwinulids, together with the Bdelloid rotifers, as a putative ancient asexual lineage, defined by Maynard
Smith (1986) as "something of an evolutionary scandal".

D. stevensoni can be considered representative of all extant Darwinuloidea, as it is the only species in this group with a cosmopolitan distribution, occurring with relative abundance in a variety of habitats (Rossetti \& Martens 1996; Martens 1998). It is a small, non-marine, eurythermal and euryhaline benthic ostracod that occasionally appears in coastal lagoons (Griffiths \& Butlin 1994; Geiger et al. 1998; Mezquita et al. 1999). Although, according to Ranta (1979), D. stevensoni avoids running water, it has been found in riverine environments (Brady \& Robertson 1870; Rossi et al. 1998; Mezquita et al. 1999) and is considered a lotic microcrustacean by Dole-Olivier et al. (2000). Although a correlation between morphologic variability and habitat salinity is described in ostracods (Carbonel et al. 1988; Geiger et al. 1998; Yin et al. 1999), Rossetti \& Martens (1996) did not find significant variability in size and shape of the carapace and soft parts of D. stevensoni from six populations from Europe (Finland, Belgium, Austria, Italy) and one from South Africa, from water bodies whose salinity ranged from $86 \mu \mathrm{S} \mathrm{cm}^{-1}$ to 3440 $\mu \mathrm{S} \mathrm{cm}^{-1}$. Gandolfi et al. (in press) described the salinity tolerance of $D$. stevensoni and reported that the median 
lethal time (LT50) of females from different populations is not related to the chemical characteristics of the sampling site. Morphological uniformity is coupled with very low genetic variability. Schön et al. (1998) found no variation in nuclear (ITS1) DNA sequences and described a very low substitution rate in sequences of mitochondrial (COI) DNA among 20 populations from Africa and Europe. Rossi et al. (1998) analysed 36 populations from Finland to South Africa by allozyme markers and found high genetic similarity with the same few alleles shared at Glucose phosphate isomerase (Gpi) locus, the only polymorphic one. The low clonal diversity observed in D. stevensoni makes this species an exception to the general rule of relatively high clonal diversity for parthenogenetic ostracods (Rossi et al. 1998). From the study of a North American population (Marshfield, Missouri) Havel \& Hebert (1993) reported that only Phosphoglucomutase (Pgm) locus was polymorphic. In Europe, all clones are found in more than one locality, with the most frequent, homozygous at Gpi locus, being found almost everywhere in the biogeographic range, dominating in lacustrine and spring habitats. In Northern Italy, two less abundant clones, heterozygous at Gpi locus, are the most frequent in streams with evidence of spatial segregation between genetically different clones in lentic and lotic habitats (Rossi V., unpublished data).

D. stevensoni retains within a brood pouch, in the posterior part of the carapace, eggs and juveniles up to the first two instars, which are not actually found as free-living forms in the sediment (Ranta 1979). On the basis of studies in the field, McGregor (1969) and Ranta (1979) constructed static life tables and described the population biology of this species from two oligotrophic lakes: one, Gull lake, located in the Lower Michigan Peninsula, $\left(42^{\circ} \mathrm{N}-85^{\circ} \mathrm{W}\right)$ (McGregor 1969) and the other, Paajarvi lake, in Southern Finland $\left(61^{\circ} \mathrm{N}-25^{\circ} \mathrm{E}\right)$ (Ranta 1979). Results reported by the two authors are remarkably similar. The reproductive season lasts about five months, from spring to summer (McGregor 1969; Ranta 1979). The maximum number of eggs produced per female per year ever observed was 15 (McGregor 1969). The life cycle lasts from two (McGregor 1969) to four years (Ranta 1979), and the adult stage is reached in the third or fourth year of life.

Static data can be used as the basis for a life table only under the assumption that they are the same as would have been obtained if a single cohort had been followed. Some difficulties were encountered in studying the reproductive potential of $D$. stevensoni from field samples (distinguishing adults exhibiting the maximum production of juveniles from those which were either adding eggs or releasing new-borns (McGregor 1969)). Reproductive rates resulting from "time-specific" observations are dynamic balances between the production of new embryos and the release of juveniles (Ranta 1979). Widely spaced sampling periods may lead to erroneous estimates. Moreover, information on single individuals is lost. As reported by McGregor (1969), quantitative and experimental approaches are not only desirable but are essential in integrating field observations. On the other hand, D. stevensoni appeared to be a difficult species to handle as its long life cycle made lab experiments over several generations very difficult (Geiger et al. 1998).

Here we present data from laboratory experiments which represent the first attempt to study the life cycle of $D$. stevensoni in laboratory controlled conditions. Individuals from different populations were compared to evaluate the variability of survival and reproduction in genetically differentiated organisms from lotic and lentic habitats. The enzymatic activity of heterozygous and homozygous genotypes at Gpi locus was assayed in order to evaluate the relationship between GPI activity and fitness.

\section{METHODS}

Sampling was conducted, during spring and autumn 1996 and spring 1997, in seven different permanent habitats in Northern Italy and Central Spain (Tab. 1). Most of the samples were from lakes, two were from shallow streams, a river and a canal, and one was from a spring.

A net $(24 \times 12 \mathrm{~cm}$, mesh $126 \mu \mathrm{m})$ was used to collect samples from the sediment-water interface of the littoral area. Samples were hand sorted in the laboratory under a stereo microscope and all the Darwinula specimens found were kept in Petri dishes at $16^{\circ} \mathrm{C}$ and photoperiod 12:12 L:D and fed an ad libitum diet of the mat-forming alga Tolypothrix tenuis (Cyanobacteria) (acclimation conditions).

\subsection{Life history traits analysis}

A first life history traits analysis was carried out using ovigerous females sampled at the end of April 1996 in four different lacustrine and stream habitats: Monate, Montorfano and Mantova lakes and Corniano canal (Tab. 1). Each female was isolated, without acclimation, in a separate well of a tissue culture plate in 2 $\mathrm{ml}$ of Evian spring water $\left(580 \mu \mathrm{S} \mathrm{cm}^{-1}, \mathrm{pH}=7.2\right)$ and fed T. tenuis, at $16^{\circ} \mathrm{C}$, photoperiod 12:12 L:D. Survival and eggs production were recorded weekly for six months.

A second life history traits analysis was carried out using females sampled from September 1996 to early April 1997 in five different sites representing three different habitats: lake (Comabbio, Mantova and Monate), river (Mincio) and spring (Caveta) (Tab. 1). All the individuals collected had no eggs in their brood pouch. Individuals were kept in Petri dishes for a period ranging from 7 to 75 days in Evian spring water and fed $T$. tenuis, at $16^{\circ} \mathrm{C}$, photoperiod 12:12 L:D. We are aware that this difference in acclimation time might introduce an element of confusion in our results. As shown in section 3.3, no difference, at least in survival, was ob- 
Tab. 1. Sampling sites, type of habitat and sampling dates are reported. Conductivity, $\mathrm{pH}$ and temperature were recorded during the sampling, except in Caveta whose data are referred to April 1994 (Mezquita 1999). For each population and each sampling date, the number of females used in laboratory experiment $(\mathrm{N})$ is reported.

\begin{tabular}{lcccccc}
\hline Site & Habitat & Sampling dates & $\mu \mathrm{S} \mathrm{cm}^{-1}$ & $\mathrm{pH}$ & ${ }^{\circ} \mathrm{C}$ & $\mathrm{N}$ \\
\hline Caveta (E) & Spring & Nov 96 & 661 & 7.6 & 16.0 & 9 \\
Comabbio (I) & Lake & Apr 97 & 160 & 8.9 & 15.5 & 24 \\
Corniano (I) & Canal & Apr 96 & 490 & 7.5 & 14.3 & 14 \\
Mantova (I) & Lake & Apr 96- Sep 96 & $303-342$ & $8.6-8.5$ & $15.1-13.6$ & $10-15$ \\
Mincio (I) & River & Sep 96 & 310 & 8.4 & 13.6 & 19 \\
Monate (I) & Lake & Apr 96- Apr 97 & $106-113$ & $7.4-7.9$ & $17.7-14.7$ & $36-24$ \\
Montorfano (I) & Lake & Apr 96 & 215 & 8.1 & 15.0 & 18 \\
\hline
\end{tabular}

served between acclimated and non-acclimated females from populations with different acclimation duration. After this acclimation period each adult female was isolated in a separate well of a tissue culture plate in 2 $\mathrm{ml}$ of Evian spring water and fed $T$. tenuis at $16{ }^{\circ} \mathrm{C}$, photoperiod 12:12 L:D. Survival, egg production, observed through the thin translucent carapace, and release of free-living new-borns were recorded weekly for six months.

Given the species' long life-cycle and the difficulty of obtaining laboratory clonal lineages, we could not construct a cohort life-table; we simply built survivorship curves and observed the mean number of clutches per female and the mean number of eggs and new-borns hatching per clutch.

At the end of each life history traits analysis, surviving females were checked for genotype at Gpi locus (Rossi et al. 1993).

\subsection{Biochemical assay}

GPI enzyme activity was measured in a further sample of acclimated females from Comabbio, Mantova and Mincio. A Diagnostic Sigma kit (Phosphohexose isomerase) was used for the assay. Given the small body size of this species, the analyses were carried out on pools of 50 individuals, on five replicates from each population. Enzyme activity was expressed as units of activity per mg of total soluble proteins. Proteins were extracted as described by Corradi et al. (1995) and the total amount was spectrophotometrically determined by the Bio-Rad assay method (Bradford 1976).

\subsection{Statistical analysis}

Survival curves were compared using Survival - Life Table analysis by Wilcoxon (Gehan) non parametric test. Anova test was used to compare the duration of clutches (from observation of the first egg in the brood pouch to the releasing of the last juvenile) and the number of eggs per clutch and per female. Pair-wise comparisons were computed by Sheffè test. Hatching curves were computed, time to time, as the ratio between the cumulative number of new-borns and the total number of eggs produced per population. Hatching curves and hatching percentages were compared by Wilcoxon
(Gehan) non parametric test and by $\chi^{2}$ test, respectively. For each population the daily egg laying rate was computed as the ratio between the mean number of eggs and the mean duration of clutch per female. The correlation between daily egg laying rate and hatching percentage was calculated. All computations were carried out using the SPSS 8.0 statistical package.

\section{RESULTS}

\subsection{Life history traits of non-acclimated females}

Figure 1 shows the survival curves of non-acclimated females. In females from lakes Mantova, Montorfano and Monate, a survival rate of over $80 \%$ was observed for three months from the beginning of the experiment. Thereafter mortality progressively increased, but did not reach $100 \%$ at the end of the experiment. Females from Corniano canal showed a progressive survival decrease after 40-60 days, settling on values of $40 \%$ and reaching $100 \%$ mortality before the end of the experiment (Fig. 1). No significant overall differences were observed among populations (Wilcoxon $($ Gehan $)=6.527 ; \mathrm{df}=3 ; \mathrm{p}=0.089$ ) or among habitats (Wilcoxon $($ Gehan $)=3.490 ; \mathrm{df}=1 ; \mathrm{p}=0.617)$. In the pair-wise comparisons, the survival curves for Corniano and Montorfano were significantly different (Wilcoxon (Gehan) $=5.483 ; \mathrm{df}=1 ; \mathrm{p}=0.019$ ).

Females produced two clutches, one in the spring and one in early summer (Fig. 2). Eggs were produced continually, so that each clutch was formed of eggs at different developmental stages.

The duration of the first clutch was significantly different among populations $(F=3.065 ; \mathrm{p}=0.034)$ : females from Monate released their last juvenile later, on average after 61 days, a statistically different situation from that of Montorfano (43 days) ( $p<0.05)$ (Fig. 3-a1). There was no difference among the populations as regards the duration of the second clutch $(\mathrm{F}=1.138$; $\mathrm{p}=0.345)$, which was significantly longer than the first in females from Montorfano $(\mathrm{p}<0.01)$ and Monate $(\mathrm{p}$ $<0.01$ ) (Fig. 3-a). Differences in clutch duration were not significant among females grouped by habitat provenance.

When the data of the first and second clutches were combined, the mean number of eggs per female varied 


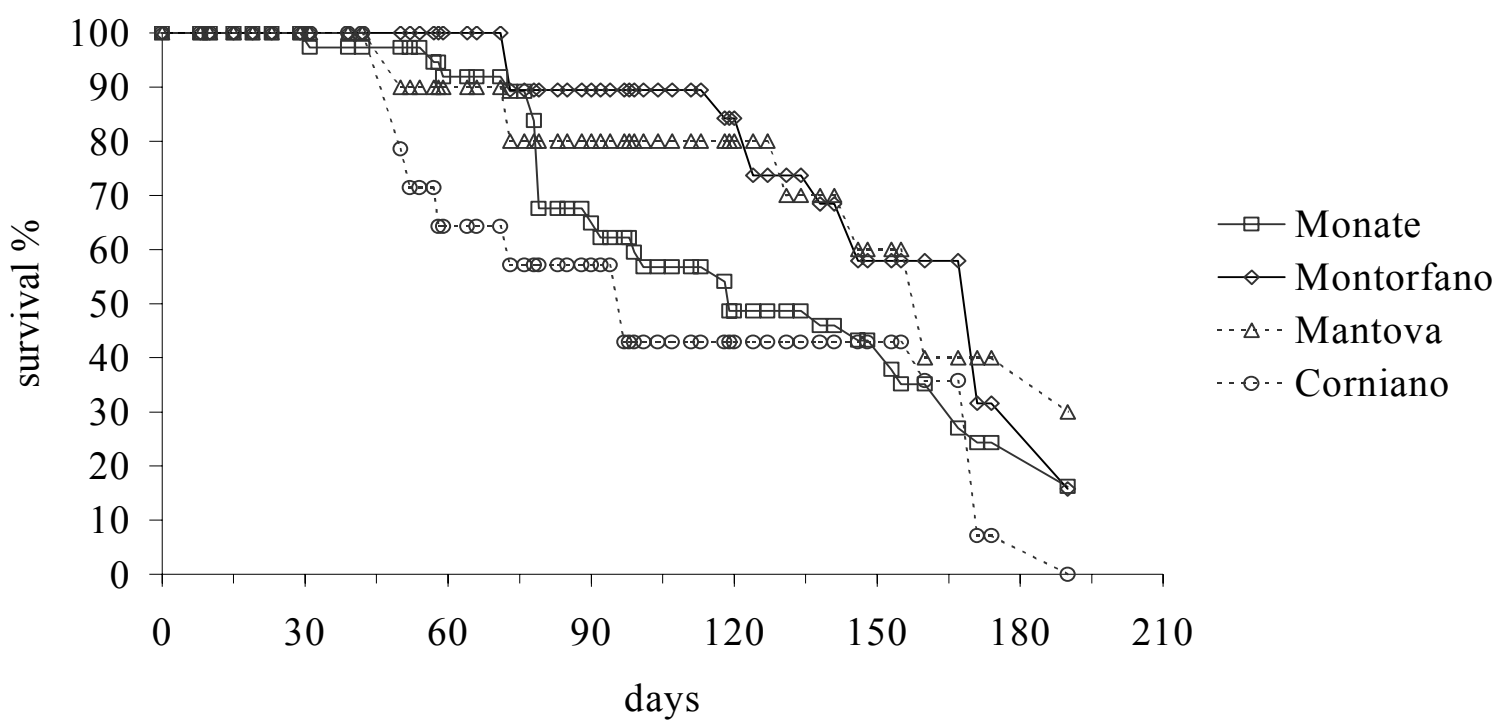

Fig. 1. Survival curves in non-acclimated females from different populations.

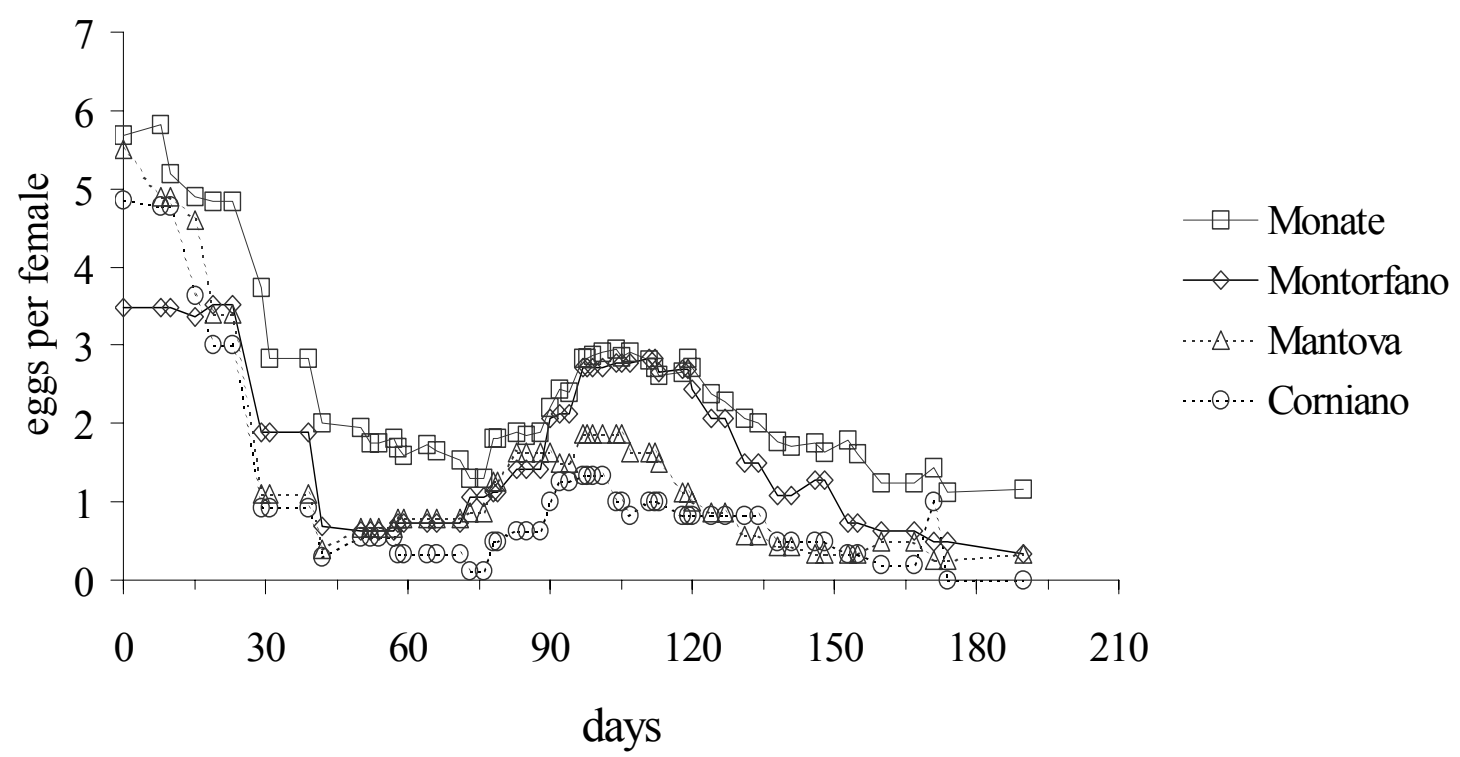

Fig. 2. Mean number of eggs per female in time in different populations of non-acclimated females.

from 5.64 (Corniano) to 8.14 (Monate), with a maximum value of 12 eggs per clutch in females from Monate (Fig. 3-b). The mean number of eggs per females was not statistically different among populations, but was higher in females from lakes than in females from riverine habitats $(\mathrm{F}=4.302 ; \mathrm{p}=0.041)$.

\subsection{Life history traits of acclimated females}

Figure 4 gives the survival curves of acclimated females. Survival was higher than $80 \%$ in the first three months in females from Caveta spring, Lake Comabbio and River Mincio, whereas it decreased to a value of about $70 \%$ in females from lakes Mantova and Monate after just one month. Before the end of the experiment, all the females from Caveta and Mincio died, but mortality settled down to values of 70,80 and $90 \%$ in organisms from Comabbio, Monate and Mantova, respectively (Fig. 4).

Differences in survival curves were significant among populations (Wilcoxon $($ Gehan $)=14.537$; df=4; $\mathrm{p}=0.006$ ). By pair-wise comparisons, the survival curve of females from Comabbio was different from that of females from Mantova (Wilcoxon $($ Gehan $)=8.671$; $\mathrm{df}=1$; 

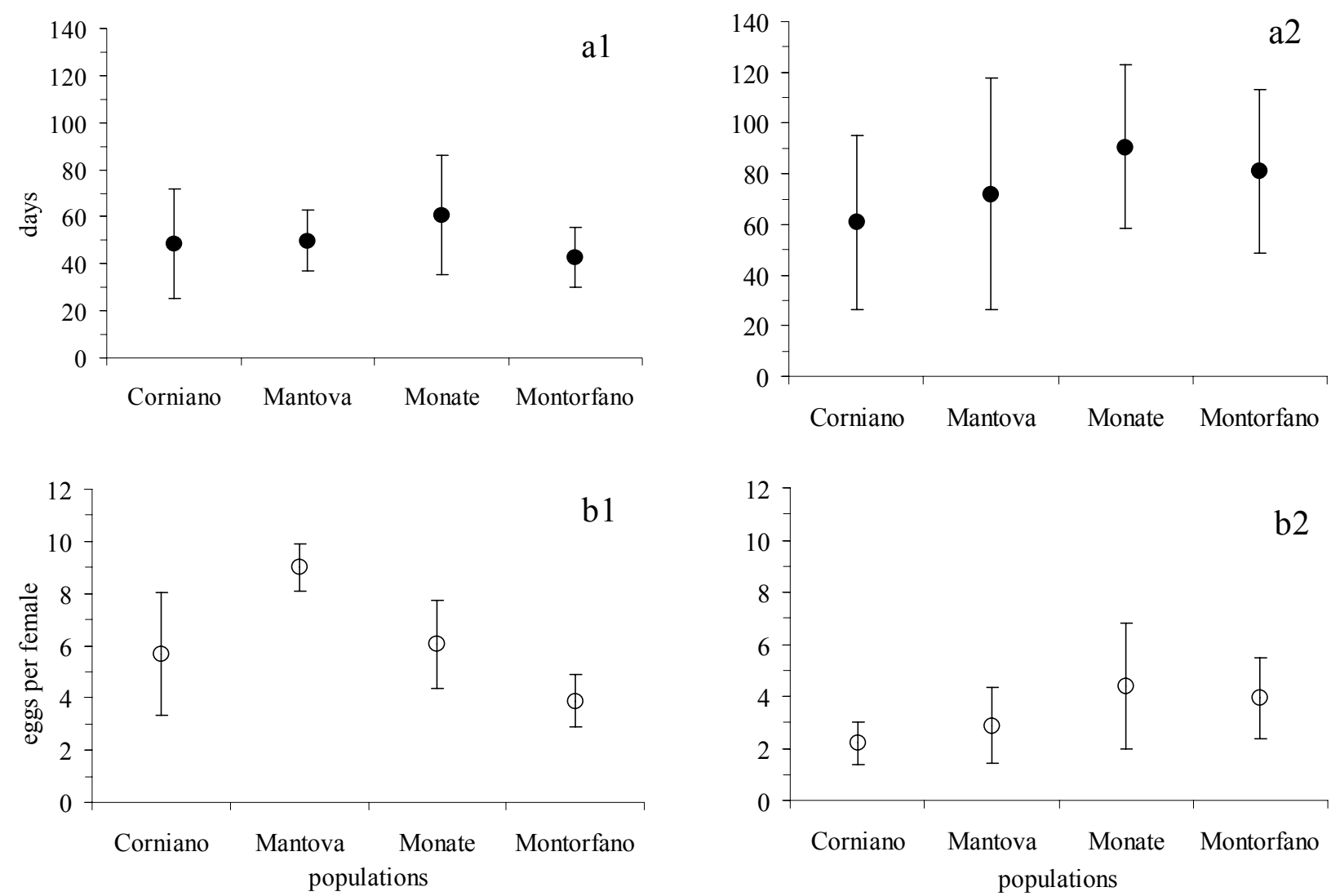

Fig. 3. Duration (a) and number of eggs (b) in non-acclimated females from different populations in the first (1) and in the second (2) clutch: mean values and standard deviations are shown.

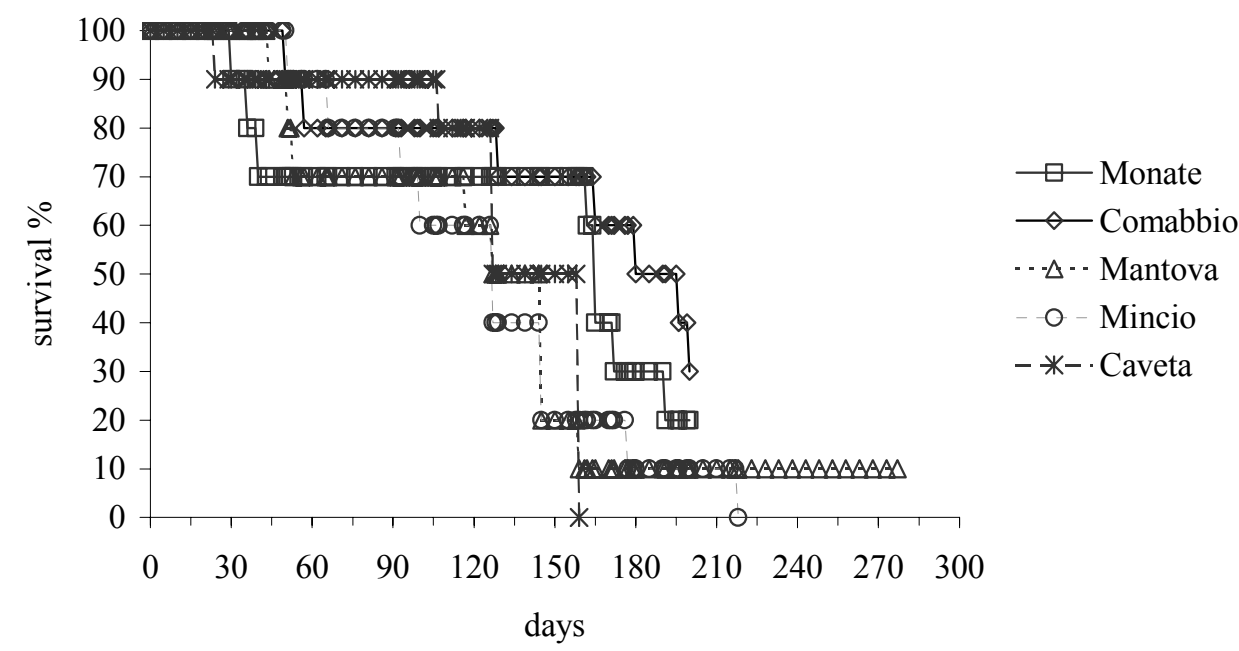

Fig. 4. Survival curves of acclimated females from different populations.

$\mathrm{p}=0.003)$, Caveta (Wilcoxon $($ Gehan $)=10.318 ; \mathrm{df}=1$; $\mathrm{p}=0.001)$ and Mincio (Wilcoxon $($ Gehan $)=6.392 ; \mathrm{df}=1$; $\mathrm{p}=0.011)$. The survival curve of females from Monate was different from that of females from Caveta (Wilcoxon $($ Gehan $)=7.800 ; \mathrm{df}=1 ; \mathrm{p}=0.005)$. Among habitats, only differences in survival curves of females from lake and river were found (Wilcoxon $($ Gehan $)=18.021 ; \mathrm{df}=1 ; \mathrm{p}<0.001)$.

Acclimated females from all populations appeared to produce only one clutch. Females from river Mincio 
started to produce eggs one month later than females from Mantova and Caveta. Clutch duration was significantly different among populations $(\mathrm{F}=5.353 ; \mathrm{p}=0.001)$ : higher in females from Caveta (127 days) and Comabbio (126 days) than in females from Mincio (60 days) (Fig. 5-a). Differences were also found among females grouped by habitat provenance $(\mathrm{F}=5.889 ; \mathrm{p}=0.004)$ : lower in females from the river habitat (60 days) than in females from the lakes $(107$ days $)(p<0.05)$ and the spring $(127$ days $)(p<0.01)$. The mean time from observation of the first egg in the brood pouch to the release of the first juvenile varied from 34 days $(\mathrm{N}=4, \mathrm{sd}=1.6)$ in females from river Mincio to 69 days $(\mathrm{N}=8, \mathrm{sd}=24)$ in females from the Caveta spring.
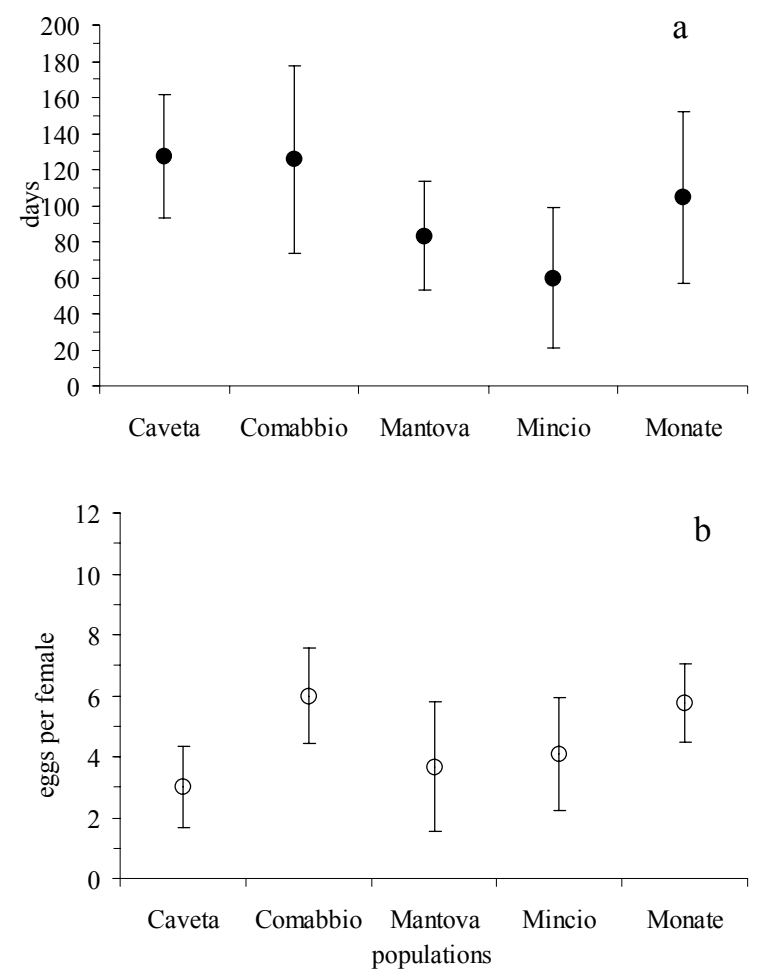

Fig. 5. Clutch duration (a) and number of eggs (b) in acclimated females from different populations: mean values and standard deviations are shown.

The mean number of eggs per female varied from 3.00 (Caveta) to 6.00 (Comabbio) with a maximum value of 9 eggs per clutch in females from Mantova (Fig. 5-b). Clutch size was significantly different among populations $(\mathrm{F}=10.151 ; \mathrm{p}<0.001)$. Females from $\mathrm{Co}-$ mabbio and Monate produced a higher number of eggs (6.00 and 5.75, respectively) than females from Mantova and Caveta (3.67 and 3.00, respectively) $(p<0.01)$. Differences in the mean number of eggs per female were significant among habitats $(\mathrm{F}=7.784 ; \mathrm{p}<0.001)$ : females from the lakes produced more eggs (5.35 \pm 1.87) than females from the spring $(3.00 \pm 1.32)$ ( $p$ $<0.01)$.
New-born percentages in respect to eggs produced by females were significantly different among populations $\left(\chi^{2}=43.703 ; \mathrm{df}=4 ; \mathrm{p}<0.001\right)$ and among different habitats $\left(\chi^{2}=31.344 ; \mathrm{df}=2 ; \mathrm{p}<0.001\right)$ (Tab. 2$)$.

Tab. 2. Hatching percentage and egg laying daily rate per population are reported. Egg laying daily rate (ELDR) was computed as ratio between mean number of eggs and mean duration of clutch per female.

\begin{tabular}{lcc}
\hline Population & Hatch $(\%)$ & ELDR \\
\hline Caveta & 0.96 & 0.024 \\
Comabbio & 0.79 & 0.048 \\
Mantova & 0.58 & 0.044 \\
Mincio & 0.41 & 0.068 \\
Monate & 0.82 & 0.056 \\
\hline
\end{tabular}

Hatching curves were significantly different among populations $($ Wilcoxon $($ Gehan $)=18.133 ; \mathrm{df}=4 ; \mathrm{p}=0.001$ ) (Fig. 6). Significantly different hatching curves were observed in the pairwise comparisons between Caveta and Mincio (Wilcoxon (Gehan) $=13.159 ; \mathrm{df}=1 ; \mathrm{p}$ $<0.001$ ), Mincio and Monate (Wilcoxon (Gehan) = 11.980; $\mathrm{df}=1 ; \mathrm{p}<0.001)$, Caveta and Comabbio (Wilcoxon $($ Gehan $)=4.972 ; \mathrm{df}=1 ; \mathrm{p}=0.026)$ and between Mincio and Comabbio (Wilcoxon (Gehan) = 8.574; $\mathrm{df}=1 ; \mathrm{p}=0.003)$.

The correlation between daily egg laying rate and hatching percentage (Tab. 2) was not significant $\left(\mathrm{R}^{2}=0.566 ; \mathrm{p}=0.1422\right)$. Only a few new-borns reached sexual maturity after one year.

\subsection{Comparison of performances of acclimated and non-acclimated females}

The populations from Mantova and Monate were the only ones analysed in both life table experiments, so that a comparison was possible only between these two cases.

Survival curves were not significatively different in Mantova or in Monate.

In both Mantova and Monate, the mean number of eggs produced by non-acclimated females was significantly higher than in acclimated ones (Mantova $\mathrm{F}=9.073, \mathrm{p}=0.006$; Monate $\mathrm{F}=9.872, \mathrm{p}=0.003$ ), whereas the mean duration of the first plus the second clutch in non-acclimated females (88 days for Mantova and 104 days for Monate) was not significantly longer than the sole clutch observed in acclimated females (83 days for Mantova and 104 days for Monate).

\subsection{Genotypic diversity and enzymatic activity}

Genotypic diversity at Gpi locus was confirmed: populations from lentic habitats were made up of heterozygous genotypes, while populations from lotic habitats were made up of homozygous genotypes.

The mean GPI activity in females from different populations was very similar: $0.659 \mathrm{U} \mathrm{mg}^{-1}$ in females 


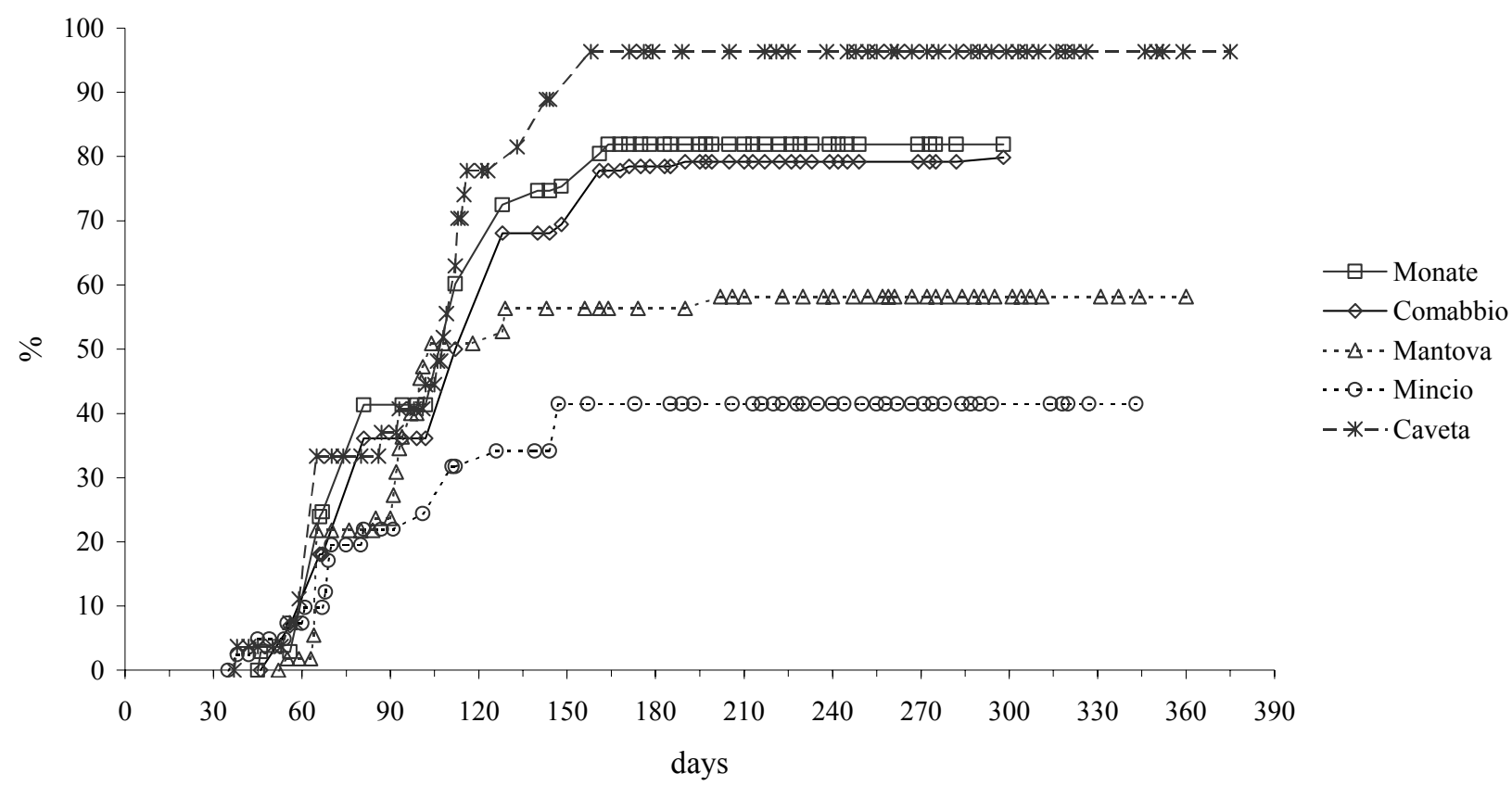

Fig. 6. Hatching curves in acclimated females.

from Comabbio, $0.496 \mathrm{U} \mathrm{mg}^{-1}$ in females from Mantova and $0.584 \mathrm{U} \mathrm{mg}^{-1}$ in females from Mincio. As a consequence, there is no difference in enzymatic activity between homozygotes (Comabbio and Mantova) and heterozygotes (Mincio) at Gpi locus.

\section{DISCUSSION}

To our knowledge, no laboratory data on the life history traits of $D$. stevensoni have been reported in the literature. Such information is the basis for a quantitative discussion of the intriguing evolutionary history of the species (Geiger et al. 1998). There are practical problems in constructing a cohort life table for an organism that, according to Ranta (1979), lives up to 3-4 years. Moreover, there was a very high mortality rate in our preliminary experiments of new-borns obtained from females maintained in laboratory conditions. The high mortality of first instars in laboratory conditions prevented us from using a cohort approach to build a proper life table for the species. Certainly, the absence of substrate, the natural environment for this benthic species, in the experiments, while it makes observations easier, is probably a source of stress for the animals in the long run (Gorokhova \& Hansson 1997). In our experiments, only a few new-borns survived at least one year, reached sexual maturity and produced 1-2 eggs.

Our results confirm most of the field observations reported by Ranta (1979) and McGregor (1969), who described a reproductive season lasting from May to September-October. Our data showed that non-acclimated females produced two clutches per reproductive season: one in early spring and one in early summer.
Eggs were produced continually and, as a consequence, each clutch was composed of embryos at different developmental stages, whose age is very hard to evaluate except from the appearance of an eye pigment. Both the first and the second clutches lasted for about two months, with an interval of one month. Juveniles released in the early summer matured and produced eggs in early spring, while juveniles released later in the summer matured and produced eggs early in the following summer.

In D. stevensoni, life span is long and age at first reproduction late if compared to other small body size species (about $0.7 \mathrm{~mm}$ ). This is easily appreciated when we compare these traits with those of other non-marine ostracods (Fig. 7) (data from McGregor 1969; McLay 1978; Ranta 1979; Gandolfi 1995; Yin 1997; Notaro 1998). According to Griffiths \& Butlin (1994), populations are typically described as steady and crowded. Indeed, we observed the temporary disappearance of Darwinula from typical sampling stations: for instance from Mantova and Mincio in spring-winter 1998. We suppose that active small scale migration enables Darwinula to lessen the effect of environmental fluctuations.

With respect to reproductive allocation, D. stevensoni produces fewer and larger offspring than other ostracod species. Its daily egg laying rate during the reproductive season is between 0.02 and 0.07 , depending on the population considered, which is lower that that observed in other species: about 1.2-1.5 in E. virens (Notaro 1998), between 2.5 and 6, according to different clones and experimental conditions, in $H$. incongruens 


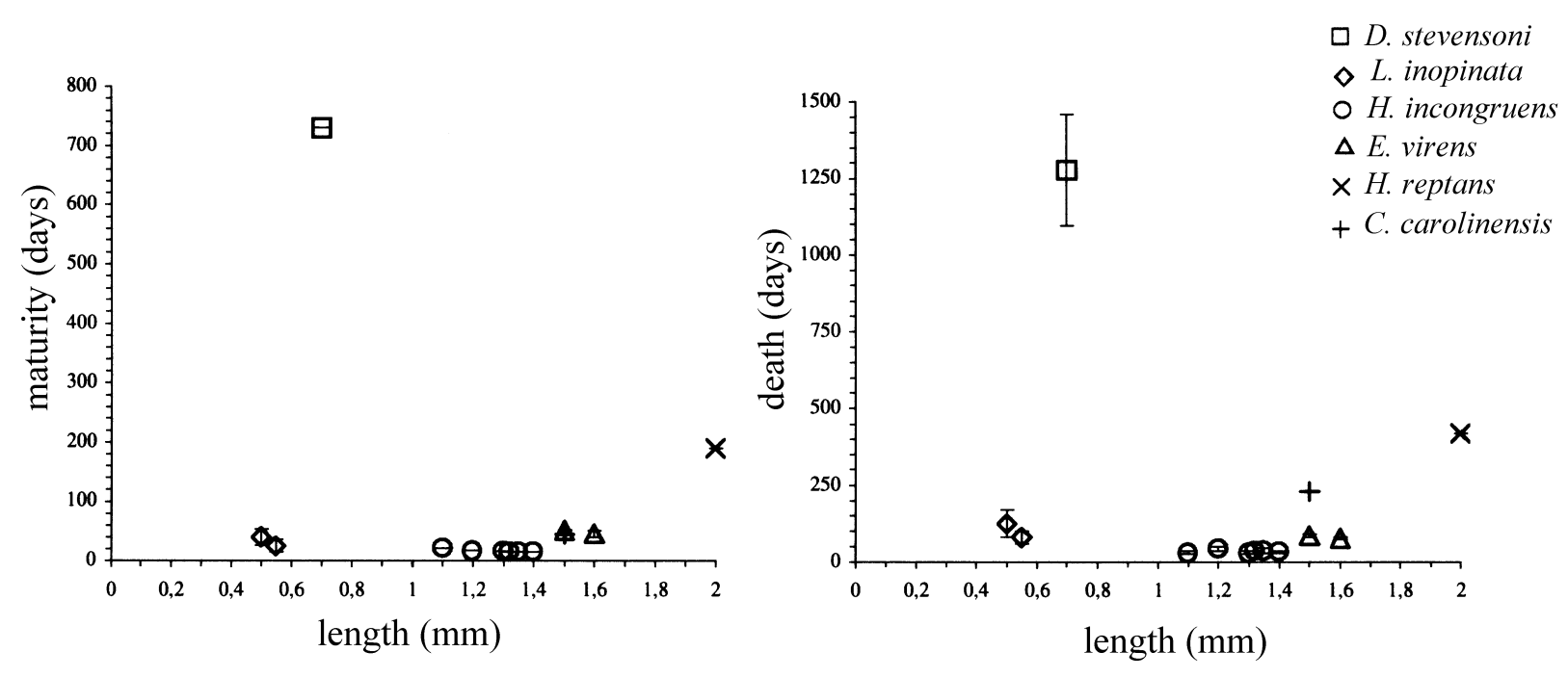

Fig. 7. Allometric relationships for adult females between maturation time (left) and life span (right) and body size in different ostracods species are reported: Limnocythere inopinata $(0.5 \mathrm{~mm})$, D. stevensoni $(0.7 \mathrm{~mm})$, Heterocypris incongruens $(1.1-1.4 \mathrm{~mm})$, Eucypris virens $(1.6-1.7 \mathrm{~mm})$, Herpetocypris reptans $(2.0 \mathrm{~mm})$. For some species, data for different clones (ecotypes) are reported. When available from original data, range of values are reported.

(Gandolfi 1995), between 0.5 and 7, according to clones and experimental conditions, in Limnocythere inopinata (Yin 1997), and about 0.5 in Herpetocypris reptans and Cyprinotus carolinensis (McLay 1978). The ratio of egg size to adult body size is approximately 0.2 in $D$. stevensoni, 0.1 in Heterocypris incongruens and 0.1 in Eucypris virens (Gandolfi, unpub. data). The occurrence of brood care in $D$. stevensoni has been well documented and its evolutionary significance has been discussed (Horne et al. 1998a, 1998b). These differences do not seem to be related to habitat stability and predictability. In fact, while $H$. incongruens, $E$. virens, $H$. reptans and C. carolinensis are typical of temporary ponds (Wiggins et al. 1980), L. inopinata, as well as D. stevensoni, is a typical species of permanent habitats (lake and river).

Our results provide information about the plasticity of life history traits that could be due to acclimation and to genetic differences among populations, as generally reported in other parthenogenetic ostracod species (Geiger et al. 1998). Survival and overall reproductive time were not affected by acclimation, while reproductive potential decreased in acclimated females from Mantova and Monate populations. Differences in survival curves among populations and between habitats are not related to the $\mathrm{pH}$ of the water or conductivity in the different sampling sites. Differences in clutch duration are significant among populations both in acclimated and non-acclimated females. After acclimation, the females maintained a seasonal timing, starting egg production in spring, possibly slightly earlier than in natural conditions. The single clutch we observed in acclimated females is probably due to the severe reduction of the naturally occurring interval between two clutches. The overall reproductive time for acclimated individuals was about five months. Individuals from a lotic habitat (Mincio) started reproduction about one month later than other females, and their clutch duration was significantly shorter than that of females from lake and spring.

In non-acclimated organisms, the mean number of eggs per female was not statistically different among populations but was higher in females from lakes than in females from streams. In general, females from lotic habitats had a shorter reproductive season, a smaller clutch size, and a lower hatching percentage than females from lentic habitats. These differences might be associated with the observed genetic diversity of populations from streams, consisting of a heterozygous clone at Gpi locus, compared to the other populations, where a homozygous clone for the same locus is dominant. But the differences in these traits are not correlated with the differences in enzymatic activities of the heterozygous and homozygous genotypes at Gpi locus, at least in nonstressed conditions (Patarnello \& Battaglia 1992). This does not rule out an overall genetic control of these traits since, in a apomictic parthenogenetic species, the whole genome is transmitted without recombination.

It is questionable whether the variability in genetic and life history traits described supports the hypothesis of the occurrence of very few successful "general purpose genotypes" (Lynch 1984), associated with the temporal and spatial diffusion of this species (Geiger et al. 1998; Martens 1998; Schön et al. 1998). According to the "general purpose genotype" hypothesis, the wide distribution of parthenogenetic species could be explained by the existence of one or a few genotypes able to exploit a wide range of habitats. This hypothesis could explain the eurytopic characteristics of $D$. steven- 
soni, its wide distribution and its "ageing without sex". In evolutionary time, clonal selection would have favoured the evolution of highly generalised genotypes, which are characterised by both broad tolerance ranges and low fitness variance for relevant physical, chemical, and biotic gradients. We might use further long term experiments or stressed conditions to evaluate whether the fitness variability between females from lotic and lentic populations is high enough to explain the dominance of homozygotes and the spatial segregation of heterozygotes at Gpi locus.

\section{ACKNOWLEDGMENTS}

We wish to thank F. Mezquita, University of Valencia, Spain, for collecting samples from Caveta, and A. Tommasi for her assistance during laboratory experiments. This research was supported by the Italian Ministero dell'Università e della Ricerca Scientifica (FIL99 and COFIN99).

\section{REFERENCES}

Birky, C.W. Jr. 1996. Heterozygosity, heteromorphy, and phylogenetic trees in asexual eukaryotes. Genetics, 144: 427-437.

Bradford, M.M. 1976. A rapid and sensitive method for the quantification of microgram quantities of protein utilizing the principle of protein-dye binding. Anal. Biochem., 72: 248-254.

Brady, G.S. \& D. Robertson. 1870. The Ostracoda and Foraminifera of tidal rivers. Annals and Magazine of Natural History, Series 4 6: 1-31.

Butlin, R.K. \& Griffiths, H.I. 1993. Ageing without sex? Nature, 364: 680.

Butlin, R.K., I. Schön \& K. Martens. 1998. Asexual reproduction in nonmarine ostracods. Heredity, 81: 473-480.

Carbonel, P., J.P. Colin., D.L. Danielopol, H. Loeffler \& I. Neustrueva. 1988. Paleoecology of limnic ostracodes: a review of some major topics. Palaeogeogr. Palaeoclimatol. Palaeoecol., 62: 413-461.

Chaplin, J.A., J.E. Havel, \& P.D.N. Hebert. 1994. Sex and ostracods. Trends Ecol. Evol., 9: 435-439.

Corradi, M.G., G. Gorbi, A. Ricci, A. Torelli, \& M. Bassi. 1995. Chromium-induced sexual reproduction give rise to a Cr-tolerant progeny in Scenedesmus acutus. Ecotox. Environ. Safe., 32: 12-18.

Dole-Olivier, M.J., D.M.P. Galassi, P. Marmonier, Creuze' Des Chatelliers. 2000. The biology and ecology of lotic microcrustaceans. Freshwat. Biol., 44: 63-91.

Gandolfi, A. 1995. Analisi del ciclo biologico e delle strategie vitali di cloni geneticamente diversi di Heterocypris incongruens (Crustacea: Ostracoda). $1^{\text {st }}$ Degree thesis, Università di Parma.

Gandolfi, A., E.B.A. Todeschi, K. Van Doninck, V. Rossi \& P. Menozzi. (2001). Salinity tolerance of Darwinula stevensoni (Crustacea: Ostracoda). Ital. J. Zool.: (in press).

Geiger, W., M. Otero \& V. Rossi. 1998. Clonal ecological diversity. In: K. Martens (Ed.), Sex and parthenogenesis: evolutionary ecology of reproductive modes in non-marine ostracods. Backhuys Publishers, Leiden: 243-256.

Gorokhova, E. \& S. Hansson. 1997. Effects of experimental conditions on the feeding rate of Mysis mixta (Crustacea, Mysidacea). Hydrobiologia, 355: 167-172.

Griffiths, H.I. \& R.K. Butlin. 1994. Darwinula stevensoni: a brief review of the biology of a persistent parthenogen. In: D.J. Horne \& K. Martens (Eds), The evolutionary ecology of reproductive modes in non-marine Ostracoda. Greenwich University Press: 27-36.

Havel, J.E. \& P.D.N. Hebert. 1993. Clonal diversity in parthenogenetic ostracods. In: K.G. McKenzie \& P.J. Jones (Eds), Ostracoda in the Earth and Life Sciences. A.A. Balkema, Rotterdam: 353-368.

Horne, D.J., D.L. Danielopol \& K. Martens. 1998a. Reproductive behaviour. In: K. Martens (Ed.), Sex and parthenogenesis: evolutionary ecology of reproductive modes in non-marine ostracods. Backhuys Publishers, Leiden: 157195.

Horne, D.J., K. Martens \& F. Moesslacher. 1998b. A short note: Is there brooding selection in Darwinula stevensoni? In: S. Crasquin, E. Braccini \& F. Lethiers (Eds), Proceedings of the $3^{\text {rd }}$ European Ostracodologists Meeting. Bull. Centr. Reserch. Explor.-Prod. Elf-Aquitaine: 34-35.

Judson, P.O. \& B.B. Normark. 1996. Ancient asexual scandals. Trends Ecol. Evol., 11: 41-46.

Lynch, M. 1984. Destabilizing hybridization, general-purpose genotype and geographic parthenogenesis. Quart. Rev. Biol., 59: 257-290.

Martens, K. 1998. Sex and ostracods: a new synthesis. In: K. Martens (Ed.), Sex and parthenogenesis: evolutionary ecology of reproductive modes in non-marine ostracods. Backhuys Publishers, Leiden: 295-321.

Maynard Smith, J. 1986. Contemplating life without sex. Nature, 324: 300-301.

McGregor, D.L. 1969. The reproductive potential, life history and parasitisms of the freshwater ostracod Darwinula stevensoni. In: J.W. Neale (Ed.), The taxonomy, morphology and ecology of recent Ostracoda. Oliver \& Boyd, Edinburgh: 194-221.

McLay, C.L. 1978. Comparative observations on the ecology of four species of ostracods living in a temporary freshwater puddle. Can. J. Zool., 56: 663-675.

Mezquita F., G. Tapia \& J.R. Roca. 1999. Ostracoda from springs on the eastern Iberian Peninsula: ecology, biogeography and palaeolimnological implications. Palaeogeogr. Palaeoclimatol. Palaeoecol., 148: 65-85.

Notaro, A. 1998. Variazioni del ciclo biologico in cloni di Eucypris virens (Crustacea: Ostracoda). $1^{\text {st }}$ Degree thesis, Università di Parma.

Patarnello, T. \& B. Battaglia. 1992. Glucosephosphate isomerase and fitness: effects of temperature on genotype dependent mortality and enzyme activity in two species of the genus Gammarus (Crustacea: Amphipoda). Evolution, 46: 1568-1573.

Ranta, E. 1979. Population biology of Darwinula stevensoni (Crustacea, Ostracoda) in an oligotrophic lake. Ann. Zool. Fennici, 16: 28-35.

Rossetti, G. \& K. Martens. 1996. Redescription and morphological variability of Darwinula stevensoni (Brady \& Robertson, 1870) (Crustacea, Ostracoda). Bull. k. bel. Inst. Natuurw. Biol., 66: 73-92.

Rossi, V., Giordano, P. \& P. Menozzi. 1993. Genetic variability in parthenogenetic populations of Heterocypris incongruens (Crustacea, Ostracoda). In: K.G. McKenzie \& P.J. Jones (Eds), Ostracoda in the Earth and Life Sciences. A.A. Balkema, Rotterdam: 369-383.

Rossi, V., I. Schön, R.K. Butlin \& P. Menozzi. 1998. Clonal genetic diversity. In: K. Martens (Ed.), Sex and parthenogenesis: evolutionary ecology of reproductive modes in non-marine ostracods. Backhuys Publishers, Leiden: 257274.

Schön, I., R.K. Butlin, H.I. Griffiths \& K. Martens. 1998. Slow evolution in an ancient asexual ostracod. Proc. $R$. Soc. Lond. B., 265: 235-242.

Schön, I., K. Martens \& V. Rossi. 1996. Ancient asexual scandal or artefact? Trends Ecol. Evol., 11: 296-297.

Sohn, I.G. 1987. The ubiquitous ostracode Darwinula stevensoni (Brady and Robertson, 1870), redescription of the 
species and lectotype designation. Micropaleontology, 33: 150-163.

Tetart, J. 1978. Les garnitures chromosomique des Ostracodes d'eau douce. Travaux du Labortoire d'Hydrobiologie et de Pisiculture de l'Universite de Grenoble, 69-70: 113-140.

Wiggins, G.B., R.J. McKay \& I.M. Smith. 1980. Evolutionary and ecological strategies of animals in annual temporary pools. Arch. Hydrobiol., Suppl. $58: 97-206$.

Received: September 2000

Accepted: December 2000
Yin, Y. 1997. Contribution to the morphology and ecology of ostracoda Limnocytheridae and Candonidae: comparative studies between Austrian and Chinese Crustacea. PhD Thesis, Univ. Vienna: $163 \mathrm{pp}$.

Yin, Y., W. Geiger \& K. Martens. 1999. Effects of genotype and environment on phenotypic variability in Limnocythere inopinata (Crustacea: Ostracoda). Hydrobiologia, 400: 85-114. 